\title{
Strong interaction between T allele of endothelial nitric oxide synthase with B1 allele of cholesteryl ester transfer protein TaqIB highly elevates the risk of coronary artery disease and type 2 diabetes mellitus
}

\author{
Zohreh Rahimi ${ }^{1,2^{*}}$, Reza Nourozi-Rad ${ }^{3}$, Ziba Rahimi ${ }^{1}$ and Abbas Parsian ${ }^{4}$
}

\begin{abstract}
Background: The present study was conducted to investigate the possible outcome of interaction between endothelial nitric oxide (NOS3) G894T and cholesteryl ester transfer TaqlB variants on the risk of coronary artery disease (CAD) and type 2 diabetes mellitus (T2DM). The sample included a total of 207 CAD patients (102 CAD patients with T2DM and 105 CAD patients without T2DM). There were also 101 patients with T2DM and 92 age- and sex-matched healthy individuals as controls. All study participants were from Western Iran. The sample was genotyped by polymerase chain reaction-restriction fragment length polymorphism.

Results: The presence of NOS3 T allele was not associated with the risk of CAD or T2DM, and the CETP B1 allele was only significantly associated with the increased risk of CAD in total CAD patients (odds ratio $(O R)=5.1$, $p=0.019)$. However, the concomitant presence of both CETP B1 and NOS3 T alleles significantly increased the risk of CAD in total CAD patients (OR $=18.1, p<0.001)$, in CAD patients without T2DM $(O R=27.1, p=0.03)$, and in CAD patients with $\mathrm{T} 2 \mathrm{DM}(\mathrm{OR}=13.5, p=0.002)$. Also, the presence of both alleles increased the risk of $\mathrm{T} 2 \mathrm{DM}(\mathrm{OR}=12$, $p=0.004)$.

Conclusions: Our findings, for the first time, indicate that NOS3 T allele strongly interacts with CETP B1 allele to augment the risk of CAD and T2DM in the population of Western Iran.
\end{abstract}

Keywords: NOS3 G894T, CETP TaqIB, CAD, T2DM, Western Iran

\section{Introduction}

Cholesteryl ester transfer protein (CETP) participates in reverse cholesterol transport by transfering cholesteryl esters from high-density lipoprotein-cholesterol (HDLC) to apolipoprotein-B containing particles in exchange for triglycerides (TG), thereby reducing the concentration of HDL-C [1-3].

\footnotetext{
* Correspondence: zrahimi@kums.ac.ir

${ }^{1}$ Medical Biology Research Center, Medical School, Kermanshah University of Medical Sciences, Daneshgah Avenue, P.O. Box 67148-69914, Kermanshah, Iran

${ }^{2}$ Department of Biochemistry, Medical School, Kermanshah University of Medical Sciences, Daneshgah Avenue, P.O. Box 67148-69914, Kermanshah, Iran

Full list of author information is available at the end of the article
}

CETP gene located on chromosome 16q21 consists of 16 exons and 15 introns and has several genetic polymorphisms affecting CETP activity among which TaqIB polymorphism has been most widely studied. This polymorphism results from $\mathrm{G}$ to $\mathrm{A}$ base pair change at nucleotide 277 in intron 1 of the CETP gene which disrupts TaqI restriction site (single-nucleotide polymorphism (SNP) rs708272). The allele containing the TaqI endonuclease site is called B1, while the allele without the restriction site is called B2. The less common B2 allele has been associated with increased HDL-C levels and decreased CETP activity and levels [4,5]. The association of CETP variants with coronary artery disease (CAD) and type 2 diabetes mellitus (T2DM) has been

\section{Biomed Central}


investigated in several studies without consistent results [1,6-9].

Nitric oxide synthase (NOS) synthesizes NO through the oxidation of L-arginine to L-citrulline which is an important regulator of vasodilator tone and blood pressure $[10,11]$. One of the most clinically important polymorphisms of NOS3, the G894T polymorphism, results from $\mathrm{G}$ to $\mathrm{T}$ conversion at nucleotide 894 of exon 7 of gene that changes Glu298Asp (SNP rs1799983). The presence of this polymorphism reduces the NO production. There are several studies reporting controversial results related to the role of NOS3 variants on the susceptibility to CAD and T2DM [12-17].

Recently, we reported that the B1 allele of CETP increased the risk of CAD and T2DM 1.65- and 1.7-fold, respectively [18]. Also, we indicated that the risk of CAD was increased by 2.15 -fold in the presence of $\mathrm{T}$ allele of NOS3 in our population [19]. To our knowledge, there is no report related to the influence of concomitant presence of CETP variants and NOS3 G894T polymorphism on the risk of CAD and T2DM in the literature.

The aim of the present study was to examine the interaction between CETP TaqIB and NOS3 G894T variants and its effect on the risk of CAD and T2DM in the population of Western Iran.

\section{Materials and methods}

The sample consisted of 308 patients and 92 controls. There were 207 total CAD patients including 113 males and 94 females with the mean age of $56.9 \pm 8.6$ years from whom there were $102 \mathrm{CAD}$ patients with T2DM (CAD/T2DM) and $105 \mathrm{CAD}$ patients without T2DM. There were 101 patients with T2DM including 51 males and 50 females with the mean age of $56.5 \pm 9.8$ years. The controls were 92 non-diabetic individuals that consisted of 47 males and 45 females with the mean age of $54.3 \pm 8.5$ years who were evaluated by angiography for suspected CAD but had normal coronary arteries. All patients and controls were recruited from Imam Ali Hospital of Kermanshah University of Medical Sciences and were from Western Iran with Kurdish ethnic background.

Patients were referred to the Cardiology Division of the Imam Ali Hospital of the Kermanshah University of Medical Sciences to undergo their first coronary angiography to evaluate the presence and extent of CAD. Coronary artery involvement was defined as a $\geq 50 \%$ diameter obstruction of a major coronary vessel. The diagnosis of diabetes in patients was confirmed using WHO criteria [20]. Written informed consent was obtained from each individual before participation in the study. The study was approved by the Ethics Committee of Kermanshah University of Medical Sciences and was in accordance with the principles of the Declaration of Helsinki (2000).

\section{Genotype analysis}

DNA was extracted from the leukocytes of the whole blood by the phenol-chloroform method as previously described in [21]. The NOS3 G894T polymorphism was detected by amplification of a region in exon 7 of the gene using the forward primer of $5^{\prime}$-AAG GCA GGA GAC AGT GGA TGG A-3' and the reverse primer of 5'-CCC AGT CAA TCC CTT TGG TGC TCA-3' and subsequent digestion with $\mathrm{MboI}$ restriction enzyme as previously described in [22].

For the detection of the CETP TaqIB genotypes, the following primers were used: 5'-CACTAGCCCAGAGA GAGGAGTGCC-3' ${ }^{\prime}$ and $5^{\prime}$ CTGAGCCCAGCCGCACA CTAAC- $3^{\prime}$ to amplify the 535-bp fragment in intron 1 of the CETP gene which was amplified by PCR, and the products were digested with TaqIB restriction endonuclease as previously described in [18].

\section{Chemical analysis}

Plasma total cholesterol (TC) and TG were measured by the standard enzymatic method (Pars Azmoon kit, Pars Azmoon Inc., Tehran, Iran), using an automated Technicon RA-1000 (Technicon Instruments Corporation, NY, USA). The plasma low-density lipoprotein-cholesterol (LDL-C) and HDL-C levels were measured using commercially available enzyme assay kits (Pars Azmoon kit, Iran).

\section{Statistical analysis}

The allelic frequencies were calculated by the chromosome counting method. The genotype and allele frequencies of CETP and NOS3 in CAD and T2DM patients were compared to controls, and the significance of differences calculated using $\chi^{2}$ test. Odds ratios (OR) were calculated as estimates of relative risk for disease and 95\% confidence intervals (CI) obtained by SPSS logistic regression software. A two-tailed Student's $t$ test was used to compare quantitative data. Statistical significance was assumed at the $p<0.05$ level. The SPSS statistical software package version 16 was used for the statistical analysis.

\section{Results}

The biochemical characteristics of patients and controls are presented in Table 1. The plasma level of LDL-C and TG was significantly higher, and HDL-C level was significantly lower in both CAD and T2DM patients compared to controls. In Table 2, the lipid profile of CAD/ T2DM patients has been compared to CAD, T2DM, and controls. Significantly higher level of TG and lower level of HDL-C were observed in CAD/T2DM patients 
Table 1 Demographic and biochemical parameters of the controls and patients

\begin{tabular}{llll}
\hline Parameters & $\begin{array}{l}\text { CAD patients with and without } \\
\text { diabetes }(\boldsymbol{n}=\mathbf{2 0 7})\end{array}$ & T2DM (n=101) & $\begin{array}{c}\text { Control subjects } \\
(\boldsymbol{n}=\mathbf{9 2})\end{array}$ \\
\hline Age (years) & $56.9 \pm 8.6^{*} \mathrm{NS}$ & $56.5 \pm 9.8$ & $54.3 \pm 8.5$ \\
Sex (M/F) & $113 / 94^{*} \mathrm{NS}$ & $51 / 50$ & $47 / 45$ \\
FBS (mg/dl) & $136.2 \pm 59.6, p<0.001$ & $162.9 \pm 71.3, p<0.001$ & $97.0 \pm 20.1$ \\
History of hypertension (\%) & $102(49.6), p<0.001$ & $29(28.7), p=0.68$ & $24(26.1)$ \\
LDL-C (mg/dl) & $96 \pm 28, p<0.001$ & $98.5 \pm 38.4, p<0.001$ & $83 \pm 18$ \\
HDL-C(mg/dl) & $47 \pm 9.3, p=0.007$ & $45.2 \pm 10.2, p<0.001$ & $49.8 \pm 5.8$ \\
TC $(\mathrm{mg} / \mathrm{dl})$ & $186 \pm 42, p=0.046$ & $185.9 \pm 45.8, p=0.09$ & $177 \pm 26$ \\
TG $(\mathrm{mg} / \mathrm{dl})$ & $177 \pm 89, p=0.038$ & $200.8 \pm 99.3, p=0.001$ & $156 \pm 48$ \\
BMl $\left(\mathrm{kg} / \mathrm{m}^{2}\right)$ & $26 \pm 2.7^{*} \mathrm{NS}$ & $26.2 \pm 2.7^{*} \mathrm{NS}$ & $26.6 \pm 3.7$ \\
\hline
\end{tabular}

Plasma fasting blood sugar (FBS), LDL-C, HDL-C, TC, and TG levels, as well as age and BMI were compared between patients and controls using two-tailed Student's $t$ test. The sex was compared between two groups by the $X^{2}$-test. NS, not significant; ${ }^{*} p>0.05$.

compared to those in CAD patients and controls. Although the level of LDL-C was higher in CAD/T2DM patients compared to those in CAD and control groups, the differences reached statistically significant values only with controls. Plasma total cholesterol was insignificantly increased in CAD/T2DM group compared to those in all studied groups. The same results were obtained when the levels of TG, HDL-C, and LDL-C were compared between T2DM patients with CAD and controls. In CAD patients, the level of LDL-C was significantly increased when compared to that in controls (Table 2). The plasma lipid and lipoprotein profiles categorized based on gender in each group are shown in Table 2. Comparison of genders in each group for lipid and lipoprotein levels indicated that women with T2DM had significantly higher plasma total cholesterol than males with T2DM (Table 2). Table 3 indicates the synergistic effect of both CETP B1 and NOS3 $\mathrm{T}$ alleles on the risk of CAD and T2DM. The concomitant presence of both alleles increased the risk of CAD significantly by 27.1-, 18.1-, and 13.5-fold in CAD patients without $\mathrm{T} 2 \mathrm{DM}$, total CAD, and CAD patients with T2DM, respectively. Also, the presence of both alleles (B1 and $\mathrm{T})$ increased the risk of T2DM by 12 -fold $(p=0.004)$ (Table 3). However, as demonstrated in Table 3, the presence of NOS3 $\mathrm{T}$ allele alone did not increase the risk of CAD or T2DM. Further, the presence of CETP B1 allele was significantly $(p=0.019)$ associated with 5.1-fold increased risk of CAD in total CAD patients.

\section{Discussion}

Diabetes mellitus is a strong risk factor for the development of atherosclerosis [6] that is related to dyslipidemia linked to insulin resistance characterized by a high triglyceride level, a high LDL-C, and a low HDL-C level [23]. In fact, decreased concentrations of HDL-C have been reported to be significantly related to CAD in patients with type 2 diabetes mellitus [7]. The significant

Table 2 Comparison of plasma lipid and lipoprotein levels in patients and controls

\begin{tabular}{lllll}
\hline Patients $(\boldsymbol{n})$ & TG $(\mathbf{m g} / \mathbf{d l})$ & TC $(\mathbf{m g} / \mathbf{d l})$ & LDL-C $(\mathbf{m g} / \mathbf{d l})$ & HDL-C $(\mathbf{m g} / \mathbf{d l})$ \\
\hline CAD with T2DM & $202.2 \pm 87.9^{*}$ & $207.6 \pm 185.4$ & $97.8 \pm 30.8^{* *}$ & $44.7 \pm 10.5^{*}$ \\
Males (52) & $206.4 \pm 85.9$ & $225.8 \pm 253.6$ & $98.6 \pm 25.9$ & $43.8 \pm 8.2$ \\
Females (50) & $197.8 \pm 90.6$ & $188.6 \pm 56.2$ & $96.8 \pm 35.3$ & $45.6 \pm 12.5$ \\
CAD without T2DM & $151.8 \pm 83.2^{* * *}$ & $182.8 \pm 36.1$ & $94.1 \pm 25.9^{* *}$ & $49.2 \pm 7.5^{* * *}$ \\
Males (61) & $150.3 \pm 93.3$ & $184.2 \pm 37.7$ & $97.2 \pm 27.6$ & $48.2 \pm 8.2$ \\
Females (44) & $153.9 \pm 67.5$ & $180.8 \pm 34.1$ & $89.8 \pm 23.1$ & $50.4 \pm 6.1$ \\
T2DM & $200.8 \pm 99.3^{*}$ & $185.9 \pm 45.8$ & $98.5 \pm 38.4^{* *}$ & $45.2 \pm 10.2^{*}$ \\
Males (51) & $198.4 \pm 110.6$ & $175.9 \pm 41.2^{* * * *}$ & $90.9 \pm 31.3^{*}$ & $42.5 \pm 9.7^{*}$ \\
Females (50) & $203.2 \pm 87.1$ & $196.2 \pm 48.3$ & $106.2 \pm 43.3$ & $47.9 \pm 10.1$ \\
Controls & $161.5 \pm 64.5$ & $176.8 \pm 25.8$ & $82.8 \pm 17.8$ & $49.8 \pm 5.8$ \\
Males (47) & $161.1 \pm 53.5$ & $179.7 \pm 27.2$ & $80 \pm 17.4$ & $48.4 \pm 5^{*}$ \\
Females (45) & $161.8 \pm 74.8$ & $173.7 \pm 24.2$ & $51.3 \pm 6.1$ \\
\hline
\end{tabular}

${ }^{*} p<0.05$ compared to CAD without T2DM and controls; ${ }^{* *} p<0.05$ compared to controls; ${ }^{* * *} p<0.05$ compared to CAD with T2DM and T2DM; ${ }^{* * * *} p<0.05$ compared between males and females in each group. 
Table 3 The carrier odds ratio interaction between CETP B1 and NOS3 894 T alleles

\begin{tabular}{|c|c|c|c|c|c|c|}
\hline CETP B1 & NOS3 T & $\begin{array}{l}\text { Total CAD patients } n(\%) \\
\text { ORs }(95 \% \mathrm{Cl}) n=207\end{array}$ & $\begin{array}{l}\text { CAD with T2DM } n(\%) \\
\text { ORs }(95 \% \mathrm{Cl}) n=102\end{array}$ & $\begin{array}{l}\text { CAD without T2DM } n(\%) \\
\text { ORs }(95 \% \text { Cl) } n=105\end{array}$ & $\begin{array}{l}\text { T2DM patients } n(\%) \\
\text { ORs }(95 \% \mathrm{Cl}) n=101\end{array}$ & $\begin{array}{l}\text { Controls } \\
n(\%) n=92\end{array}$ \\
\hline- & - & $3(1.4)$ & $2(2)$ & $1(1)$ & $2(2)$ & $8(8.7)$ \\
\hline \multirow[t]{2}{*}{-} & + & $3(1.4)$ & $3(2.9)$ & 0 & $2(2)$ & $12(13)$ \\
\hline & & $0.67(0.11-4.17, p=0.67)$ & $1(0.14-7.4, p=1)$ & & $0.67(0.1-5.7, p=0.71)$ & \\
\hline \multirow[t]{2}{*}{+} & - & $113(54.6)$ & $53(52)$ & $60(57.1)$ & $58(57.4)$ & $59(64.2)$ \\
\hline & & $5.1(1.3-20, p=0.019)$ & $3.6(0.73-17.7, p=0.11)$ & $8.14(1-67, p=0.05)$ & $3.9(0.8-19.3, p=0.09)$ & \\
\hline \multirow[t]{2}{*}{+} & + & $88(42.6)$ & $44(43.1)$ & $44(41.9)$ & 39 (38.6) & $13(14.1)$ \\
\hline & & $18.1(4.2-76.8, p<0.001)$ & $13.5(2.6-71.8, p=0.002)$ & $27.1(3.1-237, p=0.003)$ & $12(2.25-63.8, p=0.004)$ & \\
\hline
\end{tabular}

Interaction with respect to $\mathrm{B} 2$ or $\mathrm{G}$ alleles in CAD and T2DM patients compared with controls. Overall distribution of interaction between CETP B1 and NOS3 T alleles in total CAD compared to controls $\left(x^{2}=42.4, \mathrm{df}=3, p<0.001\right)$ and between CAD with T2DM compared to controls $\left(x^{2}=25.7, \mathrm{df}=3, p<0.001\right)$, as well as comparison between CAD without T2DM and controls $\left(x^{2}=33.6, \mathrm{df}=3, p<0.001\right)$. Overall distribution of interaction between CETP B1 and NOS3 T alleles in T2DM patients compared to controls $\left(x^{2}=23.4, \mathrm{df}=3, p<0.001\right)$.

higher level of TG and lower level of HDL-C observed in CAD patients with T2DM compared to those in CAD patients without diabetes in the present study confirm the role of dyslipidemia for predicting the risk of CAD in T2DM patients.

Both genetics and environmental factors have important roles in the pathogenesis of CAD and T2DM [24]. The role of genetic factors appears to be considerably different between various populations [25].

The most commonly studied polymorphism of CETP is TaqIB with a frequency of 0.44 in Caucasian populations and is associated with decreased CETP mass, an increase in HDL-cholesterol, and modulating the risk for diabetic complications in patients with T2DM. The presence of homozygous B1 allele is associated with lowest while in B2B2 carriers there is highest HDL-cholesterol concentration $[5,26]$. The role of CETP TaqIB polymorphism on the risk of CAD and T2DM either through its influence on lipid metabolism or independent of its effect on lipid profile has been reported in various populations [1,6-9]. Previously, we reported an association between the B1 allele of CETP and the risk of CAD and T2DM independent of HDL-C level [18]. Endothelial NOS gene through coding endothelial NOS enzyme has a role in maintaining normal endothelial function. Endothelial NOS through synthesis of NO affects the relaxation of vascular smooth muscle, inhibition of adhesion of platelets and leukocytes to the endothelium, reduction of vascular smooth muscle cell migration and proliferation, and limitation of the oxidation of LDL-C $[27,28]$. There are several reports indicating an association between the NOS3 G894T polymorphism and the risk of CAD $[13,14]$. However, some studies demonstrated the lack of association between this polymorphism and the risk of CAD $[15,17,29]$. Our recent work indicated that the risk of CAD is elevated in the presence of NOS3 T allele [19]. In the present work, we examined the influence of concomitant presence of NOS3 T and CETP B1 alleles on the risk of CAD and T2DM. We noticed that the risk of CAD augments in the presence of both alleles in total CAD and in CAD patients with and without T2DM to the level of 18.1-, 13.5-, and 27.1-fold, respectively. Also, the combined presence of both alleles increased the risk of T2DM by 12-fold. Our study demonstrated that the presence of variations in more than one gene play an important role in the susceptibility to CAD and T2DM.

The presence of hypercholesterolemia and oxidized LDL-C downregulates NOS expression and rapid degradation of NO. The exact mechanism of influence of CETP variants and its interaction with NOS3 G894T polymorphism on the risk of CAD and T2DM is unclear. However, it has been suggested that contribution of CETP to the formation of small dense LDL-C particles and impairment of $\mathrm{NO}$ synthesis in the presence of NOS3 G894T variants that are enhanced in hypercholesterolemia might lead to endothelial dysfunction and atherosclerosis [30].

Briefly, our study indicated that the B1 allele of CETP TaqIB polymorphism in combination with NOS3 T allele augments the risk of CAD and T2DM in our population. The results of the present study emphasize the role of gene-gene interaction in the pathogenesis of complex disorders such as CAD and T2DM that need to be confirmed in further studies from other populations.

\section{Competing interests}

The authors declare that they have no competing interests.

\section{Authors' contributions}

ZoR designed and supervised the research, analyzed and interpreted the data, and drafted the manuscript. RNR and ZiR carried out the molecular genetic studies. AP revised the manuscript. All authors read and approved the final manuscript.

\section{Acknowledgments}

This work was performed in partial fulfillment of the Master of Science requirements of RNR in Kermanshah University of Medical Sciences and was financially supported by a grant from Kermanshah University of Medical Sciences office of Vice Chancellor for Research, Kermanshah, Iran. We would like to thank Dr. Mansour Rezaei for his statistical comments. 


\section{Author details}

${ }^{1}$ Medical Biology Research Center, Medical School, Kermanshah University of Medical Sciences, Daneshgah Avenue, P.O. Box 67148-69914, Kermanshah, Iran. ${ }^{2}$ Department of Biochemistry, Medical School, Kermanshah University of Medical Sciences, Daneshgah Avenue, P.O. Box 67148-69914, Kermanshah, Iran. ${ }^{3}$ Department of Biochemistry, Medical School, Dezful University of Medical Sciences, Azadegan Avenue, P.O. Box 6461653476, Dezful, Iran. ${ }^{4}$ Division of Neuroscience \& Behavior, NIAAA, National Institutes of Health, Rockville, Maryland 20852, USA

Received: 26 February 2012 Accepted: 23 August 2012

Published: 25 September 2012

\section{References}

1. Boekholdt SM, Sacks FM, Jukema JW, Shepherd J, Freeman DJ, McMahon AD, Cambien F, Nicaud V, de Grooth GJ, Talmud PJ, Humphries SE, Miller GJ, Eiriksdottir G, Gudnason V, Kauma H, Kakko S, Savolainen MJ, Arca M, Montali A, Liu S, Lanz HJ, Zwinderman AH, Kuivenhoven JA, Kastelein JJ: Cholesteryl ester transfer protein TaqIB variant, high-density lipoprotein cholesterol levels, cardiovascular risk, and efficacy of pravastatin treatment individual patient meta-analysis of 13677 subjects. Circulation 2005, 111:278-287.

2. de Grooth GJ, Klerkx AHEM, Stroes ESG, Stalenhoef AF, Kastelein JJ, Kuivenhoven JA: A review of CETP and its relation to atherosclerosis. $J$ lipid Res 2004, 45:1967-1974.

3. Padmaja N, Kumar RM, Balachander J, Adithan C: Cholesteryl ester transfer protein TaqIB, $-629 \mathrm{C} \rightarrow \mathrm{A}$ and $1405 \mathrm{~V}$ polymorphisms and risk of coronary heart disease in an Indian population. Clin Chim Acta 2009, 402:139-145.

4. Kashani Farid MA, Azizi F, Hedayati M, Daneshpour MS, Shamshiri AR, Siassi F: Association between CETP Taq1B and LIPC -514C/T polymorphisms with the serum lipid levels in a group of Tehran's population: a cross sectional study. Lipids in Health and Disease 2010, 9:96.

5. Dixit M, Bhattacharya S, Mittal B: Association of CETP Taql and APOE polymorphisms with type II diabetes mellitus in North Indians: a case control study. BMC Endocrine Disorders 2005, 5:7.

6. Chaaba R, Hammami S, Attia N, Smaoui M, Masmoudi AS, Mahjoub S, Ben Hamda K, Hammami M: Association of plasma cholesteryl ester transfer protein activity and polymorphism with coronary artery disease extent in Tunisian type II diabetic patients. Clin Biochem 2005, 38:373-378.

7. Hsieh MC, Tien KJ, Chang SJ, Lo CS, Hsin SC, Hsiao JY, Hsu SC, Liang HT, Chen HC, Shin SJ, Lin SR: Cholesteryl ester transfer protein B1B1 genotype as a predictor of coronary artery disease in Taiwanese with type 2 diabetes mellitus. Metabolism 2007, 56:745-750.

8. Relvas WG, Izar MC, Helfenstein T, Fonseca MI, Colovati M, Oliveira A, Ihara SS, Han SW, Jr Las Casas AA, Fonseca FA: Relationship between gene polymorphisms and prevalence of myocardial infarction among diabetic and non-diabetic subjects. Atherosclerosis 2005, 178:101-105.

9. Kawasaki I, Tahara H, Emoto M, Shoji T, Nishizawa Y: Relationship between TaqIB cholesteryl ester transfer protein gene polymorphism and macrovascular complications in Japanese patients with type 2 diabetes. Diabetes 2002, 51:871-874

10. Zintzaras E, Papathanasiou AA, Stefanidis I: Endothelial nitric oxide synthase gene polymorphisms and diabetic nephropathy: A HuGE review and meta-analysis. Genet Med 2009, 11:695-706.

11. Miyamoto $Y$, Saito $Y$, Kajiyama N, Yoshimura M, Shimasaki Y, Nakayama M, Kamitani S, Harada M, Ishikawa M, Kuwahara K, Ogawa E, Hamanaka I, Takahashi N, Kaneshige T, Teraoka H, Akamizu T, Azuma N, Yoshimasa Y, Yoshimasa T, Itoh H, Masuda I, Yasue H, Nakao K: Endothelial nitric oxide synthase gene is positively associated with essential hypertension. Hypertension 1998, 32:3-8.

12. Tamemoto H, Ishikawa S, Kawakami M: Association of the Glu298Asp polymorphism of the eNOS gene with ischemic heart disease in Japanese diabetic subjects. Diabetes Res Clin Pract 2008, 80:275-279.

13. Kerkeni M, Addad F, Chauffert M, Myara A, Ben Farhat M, Miled A, Maaroufi K, Trivin F: Hyperhomocysteinemia, endothelial nitric oxide synthase polymorphism, and risk of coronary artery disease. Clin Chem 2006, 52:53-58.

14. Motawi T, Shaker O, Taha M, Sedrak H, Nabil M: Endothelial nitric oxide synthase and angiotensinogen gene polymorphism in coronary artery diseases in Egypt. Angiology 2011, 62:191-197.
15. Liyou N, Simons L, Friedlander Y, Simons J, McCallum J, O'Shaughnessy K, Davis $\mathrm{D}$, Johnson A: Coronary artery disease is not associated with the E298D variant of the constitutive, endothelial nitric oxide synthase gene. Clin Genet 1998, 54:528-529.

16. Jaramillo PC, Lanas C, Lanas F, Salazar LA: Polymorphisms of the NOS3 gene in Southern Chilean subjects with coronary artery disease and controls. Clin Chim Acta 2010, 411:258-262.

17. Andrikopoulos GK, Grammatopoulos DK, Tzeis SE, Zervou SI, Richter DJ, Zairis MN, Gialafos EJ, Sakellariou DC, Foussas SG, Manolis AS, Stefanadis CI, Toutouzas PK, Hillhouse EW, GEMIG study investigators: Association of the $894 \mathrm{G} \rightarrow$ T polymorphism in the endothelial nitric oxide synthase gene with risk of acute myocardial infarction. BMC Med Genet 2008, 9:43.

18. Rahimi Z, Nourozi-Rad R, Vaisi-Raygani A, Saidi MR, Rahimi Z, Ahmadi R, Yarani R, Hamzehee K, Parsian A: Association between cholesteryl ester transfer protein TaqIB variants and risk of coronary artery disease and diabetes mellitus in the population of Western Iran. Genet Test Mol Biomarkers 2012, 15:813-819.

19. Rahimi Z, Nourozi-Rad A: Association of endothelial nitric oxide synthase gene variant (G894T) with coronary artery disease in Western Iran. Angiology 2012, 63:131-137.

20. World Health Organization: Part 1. Diagnosis and classification of diabetes mellitus. In Definition, Diagnosis and Classification of Diabetes Mellitus. Geneva: WHO; 1999:1-59.

21. Rahimi Z, Ghaderi M, Nagel RL, Muniz A: Prevalence of thrombotic risk factors among $\beta$-thalassemia patients from Western Iran. J Thromb Thrombolysis 2008, 26:229-233.

22. Jafari Y, Rahimi Z, Vaisi-Raygani A, Rezaei M: Interaction of eNOS polymorphism with MTHFR variants increase the risk of diabetic nephropathy and its progression in type 2 diabetes mellitus patients. Mol Cell Biochem 2011, 353:23-34.

23. Meguro S, Takei I, Murata M, Hirose H, Takei N, Mitsuyoshi Y, Ishii K, Oguchi S, Shinohara J, Takeshita E, Watanabe K, Saruta T: Cholesteryl ester transfer protein polymorphism associated with macroangiopathy in Japanese patients with type 2 diabetes. Atherosclerosis 2001, 156:151-156.

24. Felehgari $V$, Rahimi Z, Mozafari $H$, Vaisi-Raygani A: ACE gene polymorphism and serum ACE activity in Iranians type II diabetic patients with macroalbuminuria. Mol Cell Biochem 2011, 346:23-30.

25. Liu SM, Zhou X, Zheng F, Li X, Liu F, Zhang HM, Xie Y: Novel mutations found in mitochondrial diabetes in Chinese Han population. Diabetes Res \& Clin Practice 2007, 76:425-435.

26. Heilbronn LK, Noakes M, Clifton PM: Association between HDL-cholesterol and the Taq1B polymorphism in the cholesterol ester transfer protein gene in obese women. Atherosclerosis 2002, 162:419-424.

27. Bellini MH, Figueira MN, Piccoli MF, Marumo JT, Cendoroglo MS, Neto MC, Dalboni MA, Batista MC, Goes MA, Schor N: Association of endothelial nitric oxide synthase gene intron 4 polymorphism with end-stage renal disease. Nephrology 2007, 12:289-293.

28. Möllsten A, Lajer M, Jorsal A, Tarnow L: The endothelial nitric oxide synthase gene and risk of diabetic nephropathy and development of cardiovascular disease in type 1 diabetes. Molecular Genetics and Metabolism 2009, 97:80-84

29. Ragia G, Nikkolaidis E, Tavridou A, Arvanitidis KI, Kanoni S, Dedoussis GV, Bougioukas G, Manolopoulos VG: Endothelial nitric oxide synthase gene polymorphisms $-786 \mathrm{~T} \rightarrow \mathrm{C}$ and $894 \mathrm{G} \rightarrow \mathrm{T}$ in coronary artery bypass graft surgery patients. Hum Genomics 2010, 4:375-383.

30. Goff WL, Guerin M, Chapman MJ: Pharmacological modulation of cholesteryl ester transfer protein, a new therapeutic target in atherogenic dyslipidemia. Pharmacology \& Therapeutics 2004, 101:17-38.

doi:10.1186/1479-7364-6-20

Cite this article as: Rahimi et al:: Strong interaction between T allele of endothelial nitric oxide synthase with B1 allele of cholesteryl ester transfer protein TaqIB highly elevates the risk of coronary artery disease and type 2 diabetes mellitus. Human Genomics 2012 6:20. 